P-ISSN :2655-9811, E-ISSN : 2656-1964

J. Feasible., Vol. 3, No.1, Februari $2021(13-20)$

0 2019 Pusat InkubasiBisnis dan Kew irausahaan

Universitas Pamulang (PINBIKUNPAM)
Juprat r minat

FEASIBLE

\title{
Pengaruh Promotion Mix dan Brand Trust Terhadap Keputusan Pelanggan Indi Home di Wilayah Ciputat
}

\author{
Senen Abdi Santoso* \\ Fakultas Ekonomi, Universitas Pamulang; abdisantosasenen@gmail.com*
}

\begin{abstract}
Abstrak
Tujuan dari penelitian ini adalah untuk mengetahui pengaruh promotion mix dan brand trust terhadap keputusan konsumen pada produk indi Home di wilayah Ciputat. Metode dalam penelitian deskriptif kuantitatif dengan menggunakan regresi linier berganda, dengan tahapan uji asumsi klasik (normalitas data, multikolinearitas dan heteroskedastisitas), koefisien determinasi, analisis koefisien regresi linier berganda dan uji signifikan ( $t$ dan $F$ ). Hasil penelitian menunjukan bahwa bahwa secara parsial variabel promotion mix dan brand trust berpengaruh terhadap kinerja karyawan. Secara simultanjuga menunujukkan bahwa variabel budaya kerja dan berpengaruh terhadap keputusan pelanggan. Berdasarkan hasil koefisien determinasi ditemukan bahwa variabel promotion mix dan brand trust memiliki pengaruh sebesar 64,8\%, sedangkan sisanya 35,20\% dijelaskan dengan faktor atau variabel lain yang tidak diketahui dan tidak termasuk dalam analisis regresi ini, seperti harga, kualitas pelayanan dan lainnya
\end{abstract}

Kata kunci: promotion mix; brand trust; keputusan pelanggan.

\begin{abstract}
The purpose of this study was to determine the effect of promotion mix and brand trust on consumer decisions on individual Home products in the Ciputat area. The method in quantitative descriptive research using multiple linear regression, with the classical assumption test stage (data normality, multicollinearity and heteroscedasticity), the coefficient of determination, multiple linear regression coefficient analysis and significant test ( $t$ and $F$ ). The results showed that partially the promotion mix and brand trust variables had an effect on employee performance. Simultaneously, it also shows that work culture variables and influence on customer decisions. Based on the results of the coefficient of determination it was found that the variable promotion mix and brand trust had an influence of $64.8 \%$, while the remaining $35.20 \%$ was explained by other unknown factors or variables that were not included in this regression analysis, such as price, service quality and others.
\end{abstract}

Keywords: promotion mix; brand trust; customer decisions.

*) Korespondensi penulis 


\section{PENDAHULUAN}

Dunia komunikasi global saat ini tengah berkembang pesat, sehingga memberikan kemudahan terhadap manusia dalam mengakses segala informasi yang dibutuhkan. Apabila masa lalu surat menjadi media utama dalam berkomunikasi jarak jauh, meskipun masih membutuhkan waktu sesuai dengan jarak yang ditempuh. Akan tetapi saat ini semuanya dapat dilakukan dengan cara yang begitu cepat dan mudah. Interaksi antar manusia menjadi suatu hal yang bebas dan tidak lagi terhambat jarak maupun waktu. Kemudahan tersebut merupakan dampak dari terciptanya sarana komunikasi berbasis internet.

Internet merupakan suatu jaringan komputer yang dapat menghubungkan berbagai situs yang telah ada diseluruh penjuru dunia. Keunggulan internet salah satunya memiliki sifat yang global atau dapat diakses oleh masyarakat dimanapun mereka berada. Informasi yang terjadi dibelahan bumi utara dapat diketahui oleh masyarakat dibelahan bumi selatan pada waktu yang tidak berbeda lama. Globalisasi menjadi salah satu dampak dari adanya jaringan internet, karena media massa ini menjadikan batas-batas Negara diseluruh dunia menjadi semu.

Kebutuhan akan internet bagi masyarakat menuntut perusahaan PT. Telkom melakukan terobosan dengan mengeluarkan produk Indi Home nya yaitu sebagai provider internet yang dibutuhkan masyarakat.

Keputusan konsumen adalah cerminan keberhasilan dari suatu produk atau jasa, adapun yang dimaksud dengan keputusan pembelian adalah "serangkaian proses yang berawal dari konsumen mengenal masalahnya, mencari informasi tentang produk atau merek tertentu dan mengevaluasi produk atau merek tersebut seberapa baik masing-masing alternatif tersebut dapat memecahkan masalahnya, yang kemudian serangkaian proses tersebut mengarah kepada keputusan pembelian” (Tjiptono, 2014:21).

Pendapat lain diungkapkan oleh Alma (2011:96) menyatakan bahwa "Suatu keputusan konsumen yang dipengaruhi oleh ekonomi keuangan, teknologi, politik, budaya, produk, harga, lokasi, promosi, physical evidence, people dan process, sehingga membentuk suatu sikap pada konsumen untuk mengolah segala informasi dan mengambil kesimpulan berupa response yang muncul produk apa yang akan dibeli”

Banyak faktor yang dapat mempengaruhi keputusan konsumen, salah satunya adalah promotion mix (bauran promosi). Yang dimaksud dengan promosi adalah sejenis komunikasi yang memberi penjelasan yang menyakinkan calon konsumen tentang barang dan jasa (Alma, 2012:179). Sedangkan menurut Kotler dan Keller (2016:47) promosi merupakan suatu kegiatan/aktivitas yang mengkomunikasikan keunggulan produk dan membujuk pelanggan sasaran untuk membelinya.

Faktor lainnya adalah brand trust, kepercayaan merek (brand trust) adalah kemampuan merek untuk dipercaya (brand reliability), yang bersumber pada keyakinan konsumen bahwa produk tersebut mampu memenuhi nilai yang dijanjikan dan intensi baik merek (brand intention) yang didasarkan pada keyakinan konsumen bahwa merek tersebut mampu mengutamakan kepentingan konsumen. Faktor trust terhadap sebuah merek merupakan aspek krusial dalam pembentukan loyalitas merek. Mereka mendefinisikan trust terhadap sebuah merek (trust in a brand) sebagai kesediaan konsumen untuk mempercayai atau mengandalkan merek dalam situasi risiko 
dikarenakan adanya ekspektasi bahwa merek yang bersangkutan akan memberikan hasil yang positif (Tjiptono, 2014:398).

Perlitian ini bertujuan untuk mengetahui "Pengaruh Promotion Mix Dan Brand Trust Terhadap Keputusan Konsumen Indi Home Di Wilayah Ciputat”.

\section{Manajemen}

Menurut Kasmir (2016:10) "manajemen adalah mengatur atau mengelola suatu kegiatan. Untuk mencapai efisiensi serta efektivitas dalam manajemen, maka segala tindakan dan kegiatan baru sebaiknya dilaksanakan dengan pertimbangan dan perhitungan rasional. Untuk itu diperlukan langkah-langkah kegiatan dengan perumusannya secara jelas dan tegas, agar tujuan program yang dimaksudkan dapat berjalan dengan sebaik mungkin. Menurut Fahmi (2011:2) mendefinisikan manajemen sebagai suatu ilmu yang mempelajari secara komprehensif tentang bagaimana mengarahkan dan mengelola orang-orang dengan berbagai latar belakang yang berbeda-beda dengan tujuan untuk mencapai tujuan yang diinginkan. Menurut (Robbins dan Coulter, 2010:6), mengatakan bahwa yang dimaksud dengan "Manajemen adalah proses mengkoordinasi kegiatan-kegiatan pekerjaan sehingga secara efisien dan efektif dengan dan melalui orang lain".

Menurut (Handoko, 2010:8) yang mengutip dari Stoner "management Prentice", menyatakan bahwa "manajemen adalah proses perencanaan, pengorganisasian, pengarahan dan pengawasan usaha-usaha para anggota dan penggunaan sumber daya-sumber daya organisasi lainnya agar mecapai tujuan organisasi yang telah ditetapkan".

\section{Manajemen Pemasaran}

Manajeman pemasaran menurut Buchori dan Djaslim (2010:5) adalah proses perencanaan dan pelaksanaan konsepsi, penetapan harga, promosi dan distribusi gagasan, barang, dan jasa, untuk menghasilkan pertukaran yang memuaskan individu dan memenuhi tujuan organisasi.

Tjiptono (2014:3) mengatakan bahwa manajemen pemasaran merupakan sistem total aktivitas bisnis yang dirancang untuk merencanakan, menetapkan harga, dan mendistribusikan produk, jasa dan gagasan yang mampu memuaskan keinginan pasar sasaran dalam rangka mencapai tujuan organisasional.

Daryanto (2011:1) mendefinisikan pemasaran sebagai suatu proses sosial dana manajerial dimana individu dan kelompok mendapatkan kebutuhan dan keinginan mereka dengan mencipatkan, menawarkan dan bertukar sesuatu yang bernilai satu sama lain.

\section{Promotion Mix}

Menurut Alma (2012:179) promosi adalah sejenis komunikasi yang memberi penjelasan yang menyakinkan calon konsumen tentang barang dan jasa. Sedangkan menurut Kotler dan Keller (2016:47) promosi merupakan aktivitas yang mengkomunikasikan keunggulan produk dan membujuk pelanggan sasaran untuk membelinya. Dari kedua pengertian diatas maka dapat disimpulkan bahwa kegiatan promosi adalah suatu kegiatan komunikasi antara pembeli dan penjual mengenai keberadaan produk dan jasa, menyakinkan, membujuk dan meningkatkan kembali akan produk dan jasa tersebut sehingga mempengaruhi sikap dan perilaku yang mendorong kepada pertukaran dalam pemasaran.

Bauran promosi menurut Kotler dan Keller (2016: 582) adalah maketing 
communication mix yang lebih dikenal dengan istilah promotion mix, yaitu:

1. Advertising (Iklan), yaitu semua bentuk terbayar dari presentasi non personal dan promosi ide, barang atau jasa melalui sponsor yang jelas. Bentuk yang paling dikenal oleh masyarakat adalah melalui media elektronik dan media cetak.

2. Sales promotion (Promosi Penjualan), yaitu berbagai insentif jangka pendek untuk mendorong percobaan pembelian produk atau jasa. Bentuknya seperti undian, hadiah, sampel dan lain-lain

3. Events and experiences (Acara dan pengalaman), yaitu kegiatan dan program yang disponsori perusahaan yang dirancang untuk menciptakan interaksi harian atau interaksi yang berhubungan dengan merek tertentu. Bentuknya seperti festival seni, hiburan, acara amal, dan lain-lain.

4. Public Relation and publicity (Hubungan masyarakat dan publisitas) yaitu beragam program yang dirancang untuk mempromosikan atau melindungi citra perusahaan atau produk individunya. Bentuknya seperti donasi, amal, pidato, seminar, dan lain-lain.

5. Direct Marketing and database (Pemasaran langsung) yaitu penggunaan surat, telepon, faksmile, e-mail, atau internet untuk berkomunikasi secara langsung dengan atau meminta respon atau dialog dari pelanggan dan prospek tertentu.

6. Online and social media marketing (Pemasaran online dan media sosial), yaitu aktivitas online dan program yang dirancang untuk melibatkan pelanggan atau prospek dan secara langsung meningkatkan kesadaran, memperbaiki citra, atau memperoleh penjualan produk dan layanan.
7. Mobile marketing (Pemasaran mobile), yaitu bentuk khusus pemasaran online yang menempatkan komunikasi pada konsumen ponsel, smartphone atau tablet. 8. Personal Selling (Penjualan personal), yaitu interaksi tatap muka dengan satu atau lebih pembeli prospektif untuk tujuan melakukan presentasi, menjawab

\section{Brand Trust}

Menurut (Kertajaya, 2013:11) dari sudut pandang perusahaan, brand trust adalah merek yang berhasil menciptakan brand experience yang berkesan dalam diri konsumen yang berkelanjutan dalam jangka panjang, berdasarkan integritas, kejujuran dan kesantunan brand tersebut.

Menurut Darsono (2010:53), trust adalah keinginan untuk bersandar (percaya) kepada exchange partner yang dipercayai. Trust hanya elemen dalam situasi yang tidak pasti. Secara khusus, trust mengurangi ketidakpastian dalam suatu lingkungan dimana konsumen merasa kacau karena mereka tahu akan dapat bersdanar pada merek yang dipercaya. Kepercayaan terbangun karena adanya harapan bahwa pihak lain akan bertindak sesuai dengan kebutuhan dan keinginan konsumen. Ketika seseorang telah mempercayai pihak lain maka mereka yakin bahwa harapan mereka akan terpenuhi dan tidak akan kecewa. Kepercayaan seseorang tidak hanya selalu ditujukan untuk sesama manusia saja, namun dapat juga ditujukan untuk obyek tidak nyata seperti merek.

Dengan demikian kepercayaan diartikan sebagai kemauan untuk menyandarkan diri pada hubungan dengan partnernya berlandaskan atas keyakinan. Kepercayaan merupakan keinginan konsumen untuk bersandar pada perusahaan dan kemauan untuk 
menyandarkan diri pada hubungan dengan partnernya berlandaskan atas keyakinan.

\section{Keputusan Konsumen}

Keputusan pembelian merupakan serangkaian proses yang berawal dari konsumen mengenal masalahnya, mencari informasi tentang produk atau merek tertentu dan mengevaluasi produk atau merek tersebut seberapa baik masingmasing alternatif tersebut dapat memecahkan masalahnya, yang kemudian serangkaian proses tersebut mengarah kepada keputusan pembelian (Tjiptono, 2014:21). Selanjutnya Kotler dan Keller (2012:227) menambahkan bahwa, proses keputusan pembelian adalah proses lima tahap yang dilewati konsumen, dimulai dari pengenalan masalah, pencarian informasi, evaluasi alternative yang dapat memecahkan masalahnya, keputusan pembelian, dan perilaku pasca pembelian, yang dimulai jauh sebelum pembelian yang sesungguhnya dilakukan oleh konsumen dan memiliki dampak yang lama setelah itu.

\section{Hipotesis}

Hipotesis yang diuji dalam penelitian ini berkaitan dengan ada atau tidaknya pengaruh yaang signifikan dari seperangkat pembolehubah bebas kepada pemboleh ubah bergantung. Adapan hipotesis yang diuji yakni sebagai berikut:

1. $\mathrm{H}_{\mathrm{o}}$ : variiabel promotion mix tidak berpengaruh secara parsial terhadap keputusan konsumen.

$\mathrm{H}_{\mathrm{a}}$ : variiabel promotion mix berpengaruh secara parsial terhadap keputusan konsumen.

2. $\mathrm{H}_{\mathrm{o}}$ : variabel brand trust tidak berpengaruh secara parsial terhadap keputusan konsumen.

$\mathrm{H}_{\mathrm{a}}$ : variabel brand trust berpengaruh secara parsial terhadap keputusan konsumen.

3. $\mathrm{H}_{\mathrm{o}}$ : variabel promotion mix dan brand trust tidak berpengaruh secara simultan terhadap keputusan konsumen.

$\mathrm{H}_{\mathrm{a}}$ : variabel promotion mix dan brand trust berpengaruh secara simultan terhadap keputusan konsumen.

\section{METODE}

Penelitian dilakukan pada indi home di wilayah Ciputat Metode yang digunakan dalam penelitian ini adalah kuantitatif. Dengan menggunakan metode analisis regresi linier berganda. Populasi sasaran dalaam penelitian ini adalah konsumen yang menggunakan indi home yang berada di wilayah Ciputat. Adapun penentuan jumlah sampel yang dikembangkan oleh Roscoe dalam Sugiyono (2015:131) adalah ukuran sampel yang layak dalam penelitian adalah antara 30 sampai dengan 500. Sedangkan menurut Frankel dan Wallen dalam Amiyani (2016:06) menyarankan besar sampel minimum untuk penelitian deskriptif sebanyak 100. Maka, berdasarkan teori tersebut sampel yang menjadi acuhan oleh peneliti sebanyak 100 responden. Sampel yang penulis masukkan dalam penelitian adalah sebanyak 100 pelanggan dengan menggunakan probability sampling. Pengumpulan data dilakukan dengan cara dokumentasi, wawancara dan kuesioner.

\section{HASIL dan PEMBAHASAN \\ Hasil \\ Uji Validitas \\ Berikut hasil uji validitas:}

Tabel 1. Hasil Uji Validitas

\begin{tabular}{|l|c|c|c|}
\hline Item Pertanyaan & $\begin{array}{c}\text { Corrected Item- } \\
\text { Total Correlation } \\
\left(\mathbf{r}_{\text {bitung }}\right)\end{array}$ & $\mathbf{r}_{\text {tahel }}$ & Keterangan \\
\hline Promotion MLx $\left(\mathbf{X}_{1}\right)$ & \multicolumn{3}{|l|}{} \\
\hline PM1 & 0,730 & 0,195 & Valid \\
\hline PM2 & 0,755 & 0,195 & Valid \\
\hline PM3 & 0,787 & 0,195 & Valid \\
\hline PM4 & 0,786 & 0,195 & Valid \\
\hline PM5 & 0,643 & 0,195 & Valid \\
\hline PM6 & 0,705 & 0,195 & Valid \\
\hline PM7 & 0,739 & 0,195 & Valid \\
\hline PM8 & 0,764 & 0,195 & Valid \\
\hline PM9 & 0,729 & 0,195 & Valid \\
\hline PM10 & 0,720 & 0,195 & Valid \\
\hline
\end{tabular}

http://openjournal.unpam.ac.id/index.php/jfb/index 


\begin{tabular}{|l|l|l|l|}
\hline Brand Trust $\left.\mathbf{X}_{\mathbf{2}}\right)$ \\
\hline BT1 & 0,709 & 0,195 & Valid \\
\hline BT2 & 0,805 & 0,195 & Valid \\
\hline BT3 & 0,718 & 0,195 & Valid \\
\hline BT4 & 0,716 & 0,195 & Valid \\
\hline BT5 & 0,623 & 0,195 & Valid \\
\hline Keputusan Pelanggan (Y) \\
\hline KK1 & 0,618 & 0,195 & Valid \\
\hline KK2 & 0,662 & 0,195 & Valid \\
\hline KK3 & 0,711 & 0,195 & Valid \\
\hline KK4 & 0,653 & 0,195 & Valid \\
\hline KK5 & 0,720 & 0,195 & Valid \\
\hline KK6 & 0,656 & 0,195 & Valid \\
\hline KK7 & 0,725 & 0,195 & Valid \\
\hline KK8 & 0,685 & 0,195 & Valid \\
\hline KK9 & 0,426 & 0,195 & Valid \\
\hline KK10 & 0,534 & 0,195 & Valid \\
\hline KK11 & 0,695 & 0,195 & Valid \\
\hline KK12 & 0,633 & 0,195 & Valid \\
\hline
\end{tabular}

Dari hasil uji validitas tersebut, diperoleh data yang menyatakan bahwa dari item pertanyaan yang diberikan kepada 100 responden ditemukan nilai Corrected ItemTotal Correlation ( $\mathrm{r}_{\text {tabel }}$ ) lebih besar dari nilai $0,195\left(\mathrm{r}_{\text {tabel }}\right)$ yang berarti valid maka dapat dilanjutkan ke penelitian berikutnya.

\section{Uji Reliabilitas}

Berikut hasil uji reliabilitas:

Tabel 2. Hasil Uji Reliabilitas

\begin{tabular}{|l|c|c|c|}
\hline \multicolumn{1}{|c|}{ Item Pertanyaan } & $\begin{array}{c}\text { Cronbach's } \\
\text { Alpha }\end{array}$ & $\begin{array}{c}\text { NOf } \\
\text { Item }\end{array}$ & Keterangan \\
\hline Promotion Mix $\left(\mathrm{X}_{1}\right)$ & 0,932 & 10 & Reliabel \\
\hline Brand Trust $\left(\mathrm{X}_{\mathbf{2}}\right)$ & 0,880 & 5 & Reliabel \\
\hline Keputusan Pelanggan $(\mathrm{Y})$ & 0,910 & 12 & Reliabel \\
\hline
\end{tabular}

Nilai cronbach alpha promotion mix $(0,932)$, brand trust $(0,880)$ dan keputusan pelanggan $(0,910)$, maka seluruh variabel di atas 0,70, maka dinyatakan reliabel.

\section{Uji Asumsi Klasik}

\section{Uji Normalitas}

1) Analisis Grafik

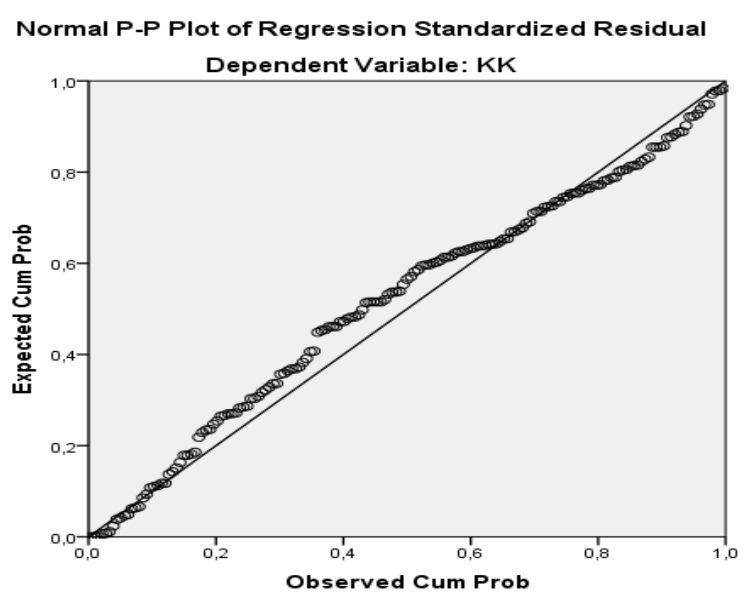

Gambar 1. Normalitas Secara Grafik

Grafik di atas dinyatakan normal, arena titiknya berada mengikuti garis diagonal.

2) Analisis Statistik

Tabel 3. Normalitas Secara Statistik

\begin{tabular}{|ll|r|}
\hline \multicolumn{2}{|c|}{ One-Sample Kolmogorov-Smirnov Test } \\
\hline N & & Unstandardized Residual \\
\hline Normal Parameters ${ }^{\text {a. }}$ & Mean & 171 \\
& Std. Deviation & $0 \mathrm{E}-7$ \\
& Absolute &, 30544726 \\
Most Extreme Differences & Positive &, 091 \\
& Negative &, 049 \\
Kolmogorov-SmirnovZ & &,- 091 \\
Asymp. Sig. (2-tailed) & 1,196 \\
\hline a. Test distribution is Normal. &, 114 \\
\hline b. Calculatitedffrom data. & \\
\hline
\end{tabular}

Nilai Asymp. Sig. $(0,114)>0.05$, ini membuktikan data bersifat normal.

\section{Uji Multikoolinearitas}

\section{Tabel 4. Hasil Uji Multikoolinearitas}

\begin{tabular}{|c|c|c|c|}
\hline \multicolumn{4}{|c|}{ Coefficients } \\
\hline \multirow{2}{*}{\multicolumn{2}{|c|}{ Model }} & \multicolumn{2}{|c|}{ Collinearity Statistics } \\
\hline & & Tolerance & VIF \\
\hline \multirow{3}{*}{1} & (Constant) & & \\
\hline & $P M$ & 701 & 1,427 \\
\hline & BT & ,701 & 1,427 \\
\hline
\end{tabular}

Nilai tolerance di atas 0,10 dan nilai VIF di bawah 10, maka dinyatakan tidak terjadi multikolinearitas. 


\section{Uji Heteroskesdastisitas}

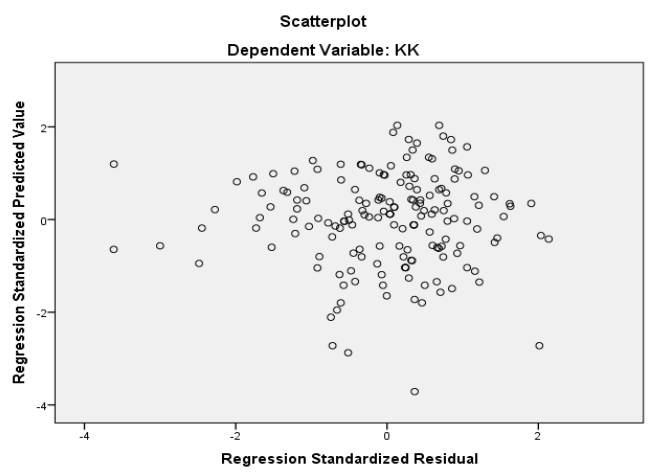

Gambar 2. Heteroskedastisitas

Terlihat bahwa titik-titik menyebar tidak beraturan, tidak mengumpul dan tidak membentuk pola, hal ini menyatakan bahwa tidak terjadi heteroskedastisitas.

\section{Uji Hipotesis}

\section{Hasil Uji t}

Hasil hipotesis dalam ujian ini adalah seperti berikut:

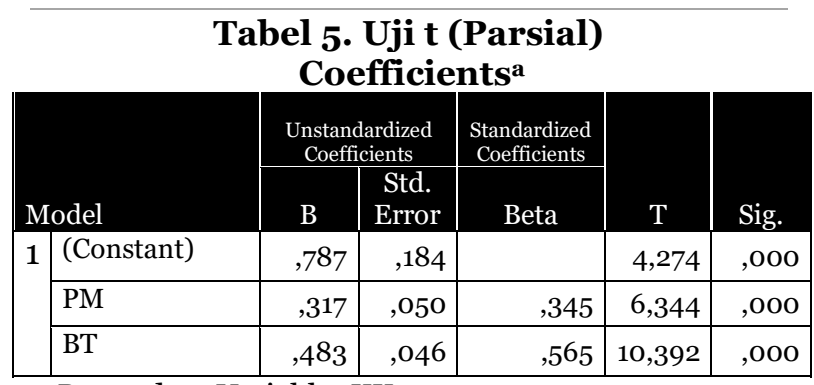

a. Dependent Variable: KK

Hasil pengolahan data menyatakan bahwa promotion mix dan brand trust berpengaruh secara parsial terhadap keputusan pelanggan.

\section{Hasil Uji F}

Tabel 6. Uji F (Simultan)

\begin{tabular}{|c|c|c|c|c|c|c|}
\hline \multicolumn{7}{|c|}{ ANOVA } \\
\hline Mo & & Sum of Squares & $\overline{d f}$ & Mean Square & $\bar{F}$ & Sig. \\
\hline \multirow{3}{*}{1} & Regression & 29,697 & 2 & 14,849 & 157,281 &, $000^{\circ}$ \\
\hline & Residual & 15,861 & 168 &, 094 & & \\
\hline & Total & 45,558 & 170 & & & \\
\hline
\end{tabular}

Berdasarkan tabel di atas nilai $\mathrm{F}_{\text {hitung }}$ $(157,281)$ lebih besar dari $F_{\text {tabel }}(3,089)$ dan nilai Sig. (o,0oo) di bawah o,005, hal ini membuktikan bahwa promotion mix dan brand trust berpengaruh secara simultan terhadap keputusan pelanggan.

\section{Regresi Linier Berganda}

Tabel 7. Hasil Koefisisen Regresi Linier

\begin{tabular}{|c|c|c|c|c|}
\hline \multicolumn{5}{|c|}{ Coefficients } \\
\hline \multirow{2}{*}{\multicolumn{2}{|c|}{ Model }} & \multicolumn{2}{|c|}{ Unstandardized Coefficients } & \multirow{2}{*}{\begin{tabular}{|c} 
Standardized Coefficients \\
Beta \\
\end{tabular}} \\
\hline & & $\mathrm{B}$ & Std. Error & \\
\hline \multirow{3}{*}{1} & (Constant) & ,787 & 184 & \\
\hline & PM & 317 &, 050 & 345 \\
\hline & BT & 483 & 046 & .565 \\
\hline
\end{tabular}

Berdasarkan hasil yang diperoleh dari pekali regresi di atas, persamaan regresi boleh dibuat seperti berikut: $\mathbf{Y}=\mathbf{0 , 7 8 7}+$ $\mathbf{0 , 3 1 7} X_{1}+\mathbf{0 , 4 8 3} X_{2}$

\section{Koefisien Determinasi $\left(R^{2}\right)$}

Tabel 8. Koefisien Determinasi

\begin{tabular}{|c|c|c|c|c|c|}
\hline \multicolumn{6}{|c|}{ "Model'Summary" } \\
\hline Model & $R$ & R Square & \begin{tabular}{|l|} 
Adjusted \\
R Square
\end{tabular} & \begin{tabular}{|l|} 
Std. Error of \\
the Estimate
\end{tabular} & Durbin-Watson \\
\hline 1 & $.8077^{8}$ & 652 & 648 & 30726 & 1,809 \\
\hline
\end{tabular}

Dari tabel di atas dapat diketahui koefisien determinasi (Adjusdted $R$ Square) sebesar 0,648 atau $64,8 \%$. Hasil tersebut memberi pengertian bahwa variabel dependen yaitu keputusan pelanggan dapat dijelaskan oleh variabel independen yang terdiri dari promotion mix dan brand trust dengan nilai sebesar 64,8\% sedangkan sisanya $35,20 \%$ dijelaskan oleh variabel independen lainnya yang tidak dimasukkan dalam model penelitian ini, seperti harga, kualitas pelayanan dan lainnya.

\section{SIMPULAN}

Hasil uji $\mathrm{t}$ (sebagian) didapati promotion mix mempengaruhi terhadap keputusan pelanggan dan brand trust 
mempengaruhi terhadap keputusan pelanggan.

Hasil uji F (serentak) didapati promotion mix dan brand trust mempengaruhi keputusan pelanggan

Sebaiknya perusahaan lebih meningkatkan promotion mix dengan cara menyebarkan brosur, menayangkan iklan di TV, radio, media sosial, mempermudah proses pemasangan, peningkatan kualitas layanan agar promosi yang dijelaskan lebih baik dan memberikan pelatihan bagi karyawan agar lebih baik menjelaskan mengenai produk yang akan dijelaskan.

Meningkatkan kepercayaan terhadap produk Indi Home dengan cara memberikan kualitas layanan jasa yang lebih baik, mempermudah proses pembayaran dengan baik, memberi keamanan bagi pelanggan dalam hal keamanan internet.

\section{DAFTAR PUSTAKA}

Alma, Buchori 2012. Manajemen Pemasaran dan Pemasaran Jasa. Alfabeta. Bandung.

Darsono dan Ashari. 2010. Pedoman Praktis Memahami Laporan Keuangan. Penerbit Andi. Yogyakarta.

Daryanto. 2011. Penelitian Tindakan Kelas dan Penelitian Tindakan Sekolah. Yogyakarta: GAVA MEDIA.

Fahmi, Irham. 2011. Analisis Laporan Keuangan. Bandung : Alfabeta.

Ghozali, Imam. 2013. Aplikasi Analisis Multivariate dengan SPSS Versi 19. Semarang: Badan Penerbit UNDIP.

Handoko, T. Hani. (2010). Manajemen Personalia \& Sumber daya Manusia. BPFE-Yogyakarta.
Kertajaya, Hermawan. 2013. Tourism Marketing 3.o. Jakarta: PT Gramedia Pustaka Utama.

Kotler Philip dkk, 2012, Manajemen Pemasaran Perspektif Asia, Buku Dua, Edisi Pertama, Andy, Yogyakarta.

Kotler, Philip and Kevin Lane Keller, 2016. Marketing Managemen, 15th Edition, Pearson Education,Inc.

Robbins, Stephen P. dan Coulter, Mary. 2010. Manajemen Edisi Kesepuluh. Jakarta: penerbit Erlangga.

Sugiyono (2015). Metode Penelitian Kombinasi (Mix Methods). Bandung: Alfabeta.

Tjiptono, Fandy, 2014. Strategi Pemasaran, Yogyakarta, Andi. 